\title{
PERMANÊNCIA NA CARREIRA DOS PROFISSIONAIS DE SEGURANÇA PÚBLICA: UM ESTUDO COM O EFETIVO DA GUARDA CIVIL METROPOLITANA DE SÃO PAULO
}

\author{
THE PERMANENCE IN THE CAREER OF PUBLIC SECURITY PROFESSIONALS: \\ A STUDY ON THE CORPORATION OF THE METOPOLITAN CIVIL GUARD OF SAO PAULO
}

\begin{abstract}
FABIAN DE SOUZA SILVA
Universidade Metodista de São Paulo

Mestre em Administração pela Universidade Metodista de São Paulo

Orcid: http://orcid.org/0000-0001-8064-8461 / E-mail: silvafabian@ig.com.br

LUCIANO VENELLI-COSTA

Universidade Presbiteriana Mackenzie - Doutor em Administração pela Universidade de São Paulo Professor do curso de Administração da Universidade Presbiteriana Mackenzie Orcid: http://orcid.org/0000-0001-9811-1582 / E-mail: luciano.venelli@gmail.com

\section{ALMIR MARTINS VIEIRA}

Universidade Metodista de São Paulo - Doutor em Educação pela UNESP

Professor do PPG em Educação - Universidade Metodista de São Paulo

Orcid: http://orcid.org/0000-0002-0523-3976 / E-mail: almir.vieira@gmail.com

Endereço: Rua do Sacramento, 230 - Rudge Ramos - CEP 09640-000 - São Bernardo do Campo - SP

\section{LAUDELINO SIQUEIRA AMARAL SANEMATSU}

Universidade Metodista de São Paulo

Mestre em Administração e doutorando em Psicologia da Saúde - Universidade Metodista de São Paulo Orcid: http://orcid.org/0000-0002-3201-3717 / E-mail: laudelinosanematsu@gmail.com
\end{abstract}

\section{RESUMO}

Este artigo tem por objetivo identificar os níveis de percepção de sucesso na carreira, de comprometimento organizacional afetivo, de entrincheiramento organizacional e de intenção de permanecer na carreira segundo a percepção de profissionais pertencentes à Guarda Civil Metropolitana de São Paulo (GCM-SP). O trabalho leva em conta o contexto profissional dos indivíduos, uma vez que, no Brasil, a carreira dos profissionais de segurança pública é considerada uma profissão de alto risco à vida. O conceito de percepção de sucesso na carreira está relacionado à interpretação do indivíduo sobre a construção de carreira em suas diversas dimensões. Esta interpretação de sucesso na carreira varia de pessoa para pessoa, ou seja, é individual e única. Assumiu-se abordagem quantitativa, por meio de um estudo elaborado com corte transversal, do qual participaram profissionais da GCM-SP, por meio de aplicação de questionário eletrônico. Os dados demonstraram que o profissional da GCM-SP tem baixa percepção de sucesso objetiva, pois $68 \%$ dos respondentes desconsideraram itens que representam o fator da dimensão objetiva da percepção de sucesso na carreira. A dimensão objetiva do sucesso na carreira se refere aos resultados relativamente visíveis da carreira, como remuneração e promoção. Conclui-se que o profissional da GCM-SP se identifica com algumas variáveis da dimensão subjetiva da percepção de sucesso na carreira, não permitindo assumir que esta dimensão é um forte influenciador na intenção de permanecer na carreira de profissionais de segurança pública.

Palavras-chave: Permanência na carreira. Comprometimento organizacional afetivo. Entrincheiramento organizacional.

Data de submissão: 11/01/2019. Data de aceite: 05/11/2019. Data de publicação: 20/12/2019. 


\section{ABSTRACT}

The purpose of this article is to identify the factors that motivate the retention of citizen security officials in a profession that presents a high risk of death for themselves, as well for their family: Guarda Civil Metropolitana de São Paulo (GCM-SP). The research took into account aspects such as perceived career success, affective organizational commitment and career retention. The theoretical background assumes that perceived career success is related to the way someone interprets his/her career, considering multiple dimensions. This phenomenon is individual and unique. In terms of methodology, this work presents a quantitative approach, with the following constructs: career success perception, organizational entrenchment, affective organizational engagement and, additionally, two variables to evaluate the intention to remain in the organization. Different characteristics have been identified between new and experienced police professionals, as well as relationships between the constructs and the intention to remain in the police career. The conclusions can guide management actions in citizen security, especially regarding the commitment and retention of current and future professionals; Understanding of the reasons that lead professionals to remain in high-risk occupations and contribute with research on retention of professionals.

Keywords: Career retention. Affective organizational commitment. Organizational entrenchment.

\section{INTRODUÇÃO}

A carreira dos profissionais de segurança pública no Brasil é considerada uma profissão de alto risco à vida. As notícias relacionadas à violência são diárias e uma parcela significativa das vítimas é o policial. Há que se reconhecer, no entanto, que outras profissões também oferecem risco direto à integridade física de seus colaboradores, com resultados semelhantes aos profissionais que atuam na área de segurança pública. No caso específico deste trabalho, tratar-se-á de aspectos concernentes à carreira do profissional pertencente à Guarda Civil Metropolitana de São Paulo (GCM-SP).

Segundo Coetzee e Esterhuizen (2010), na escolha da carreira, o debate constante se concentra na percepção prévia das expectativas do colaborador diante da organização, buscando assim a satisfação de suas necessidades pessoais, o que pode provocar reflexão na análise da fidelização à carreira na GCM-SP, posto que os profissionais desta organização, em sua grande maioria, nela permanecem até sua aposentadoria.

A importância da carreira dos profissionais de segurança pública é notada primeiramente pelo próprio guarda civil, a partir da consciência de seu compromisso, responsabilidade e risco de acertar e errar perante a sociedade. Este profissional carrega diariamente o estereótipo (assim como os médicos, engenheiros, pilotos de avião, entre outros) daquele que não pode errar. Sua crença e expectativa em relação à sua vida pessoal e profissional são constantemente munidas pela alta carga de componentes psíquicos e comportamentais inerentes à função.

A remuneração e a rígida hierarquia se configuram em peculiaridades desse tipo de profissão. O salário baixo, na maioria das corporações de segurança pública no Brasil, dificulta a retenção de talentos, assim como a rigidez na relação do poder decorrente da composição hierárquica e sobre esse aspecto é razoável reconhecer que nem todas as pessoas estão dispostas a ser submetidas a uma relação de trabalho na qual pouco se manifesta sua opinião. Ademais, é provável que os investimentos realizados durante a carreira, como treinamento, 
tempo, ascensão hierárquica e vínculo afetivo com a instituição de segurança aumentem a carga emocional na decisão de buscar novas possibilidades profissionais, como já sinalizaram Fernandes, Venelli-Costa, Vieira e Amorim (2014).

Assim, considerando algumas dimensões comportamentais dos profissionais de segurança pública, busca-se encontrar uma explicação razoável que justifique a permanência deste profissional numa carreira de alto risco, tanto à sua vida e de seus familiares.

Pelas informações disponíveis no site do Sindicato dos Guardas Civis Metropolitanos de São Paulo - SindGuardas (2018), tem-se que em torno de 60\% do efetivo da GCM-SP, ingressante na corporação entre 1996 e 2006, ainda permanecia na referida organização em 2017. No período posterior (entre 2007 e 2017), apenas 29\% dos agentes permaneceram na carreira da GCM-SP. Ainda segundo dados disponíveis pelo SindGuardas (2018), o principal motivo da evasão de profissionais da corporação, considerando o último concurso, se refere à baixa remuneração, às novas ofertas de trabalho e ao baixo vínculo emocional entre o servidor e a instituição.

Desde a fundação da GCM-SP, em 1986, não houve análise sobre os aspectos que envolvem a permanência e saída deste servidor na instituição. A idade média do servidor da GCM-SP é de aproximadamente 45 anos, ou seja, supõe-se necessidade de rápida renovação em seu quadro de servidores. Assim, neste trabalho, tem-se como enfoque a percepção do profissional da GCM-SP com relação ao sucesso da sua carreira, ao comprometimento afetivo, e à falta de opções seguras para saída deste trabalhador da instituição, geradas por investimentos realizados em sua carreira, aspecto tratado no cenário acadêmico como "entrincheiramento".

De acordo com Bastos (2002), a intenção do colaborador em permanecer na organização tem uma relação maior com os sentimentos construídos durante a sua carreira, do que com componentes calculativos. O próprio entrincheiramento apresenta investimentos de cunho afetivo, como o receio de migrar para uma nova carreira.

Em função do cenário descrito, surgiu a seguinte questão de pesquisa: dado que a função exercida pelo profissional da Guarda Civil Metropolitana (GCM) de São Paulo oferece perigo constante para sua vida e para a vida de seus familiares, por que então permanecer nesta carreira? Para responder tal questão, este trabalho tem como objetivo identificar os níveis de Percepção de Sucesso na Carreira, de Comprometimento Organizacional Afetivo, de Entrincheiramento Organizacional e de Intenção de Permanecer na Carreira segundo a percepção de profissionais pertencentes à organização mencionada.

\section{FUNDAMENTAÇÃO TEÓRICA}

\subsection{CARREIRA E PERCEPÇÃO DE SUCESSO NA CARREIRA (PSC)}

Conforme defende Venelli-Costa (2011), a maior parte dos trabalhos classifica as carreiras por segmentos: carreira docente, carreira administrativa, carreira policial etc., porém, no mundo contemporâneo, as carreiras são menos definidas: um professor coordenando os negócios de uma escola, um comandante de uma instituição de segurança gerenciando o departamento de logística de sua unidade, um enfermeiro sendo responsável pela compra de medicamentos num hospital, para se registrar alguns exemplos. A carreira é, deste modo, um construto que obteve importância na segunda metade da Revolução Industrial, com a consolidação da importância da divisão do trabalho e com a valorização dos 
cargos (DUTRA, 2002). Com o passar do tempo, novos enfoques foram observados em relação à carreira, tendo nas ciências humanas aplicadas, o seu maior laboratório.

Trata-se, portanto de uma trajetória construída por ocupações durante a vida profissional do indivíduo, que se consolida de várias maneiras. Esta trajetória pode ser numa única ou em poucas organizações; se fundindo, como uma profissão; mas também pode ser a somatória de um caminho percorrido por um empreendedor, com papéis e ocupações diversas (DUTRA, 2002). Sendo assim, a carreira é tão única quanto as próprias pessoas e foge, portanto, de um padrão esquemático padronizado. A carreira é a soma de experiências profissionais ao longo da vida. Esta é dependente de situações organizacionais que influenciam a direção e a consolidação das carreiras (LONDON; STUMPF, 1982).

Cabe ressaltar que o conceito de percepção de sucesso na carreira (PSC) está relacionado à interpretação do indivíduo sobre a construção de carreira em suas diversas dimensões. Esta interpretação de sucesso na carreira varia de pessoa para pessoa, ou seja, é individual e única. Segundo Venelli-Costa (2011), a carreira profissional tem sido avaliada de forma objetiva, por salário e promoções; e de forma subjetiva, pela maneira como o trabalhador interpreta seus avanços na área profissional. Sendo assim, alguns dos fatores descritos podem ter grande influência na permanência do servidor de segurança pública, profissional investigado neste artigo. O sucesso na carreira está atrelado às realizações percebidas ou reais que os indivíduos têm acumulado como resultado de suas experiências de trabalho (JUDGE; CABLE; BOUDREAU; BRETZ, 1995; COSTA; VIEIRA, 2014).

\subsection{COMPROMETIMENTO ORGANIZACIONAL AFETIVO (COA)}

O comprometimento organizacional afetivo (COA) é a manifestação emocional do colaborador em relação à organização, resultante do alinhamento entre os desejos estratégicos organizacionais e a satisfação das necessidades psicológicas do indivíduo (MEYER; ALLEN; SMITH, 1993).

Esta dimensão do comprometimento organizacional ocorre principalmente quando o colaborador se sente parte importante nos processos e manifesta atitude positiva dentro da organização (BANDEIRA; MARQUES; VEIGA, 2000; FERNANDES; SIQUEIRA; VIEIRA 2014). No cenário assumido para este trabalho, é de se supor que, nas instituições de segurança pública, este fenômeno pode ocorrer provavelmente pelo forte laço dos propósitos cultuados nas corporações, sobre a importância na relação entre o profissional atuante e a sociedade por ele assistida.

Os indivíduos com vínculos afetivos à organização, normalmente são motivados e apresentam alto desempenho. Pode-se esperar que estes indivíduos faltem menos ao trabalho e contribuam de forma mais significativa no sentido dos objetivos da organização do que aqueles que não possuem vínculos dessa natureza. Meyer e Allen (1991) destacam a caracterização do comprometimento afetivo, grau em que o indivíduo se sente emocionalmente ligado, identificado e envolvido com a organização. Nesse sentido, tal qual registram Rowe e Bastos (2010), pode-se afirmar que o comprometimento organizacional afetivo resulta de um vínculo afetivo em relação à organização, com o sujeito identificandose e envolvendo-se com ela, e permanecendo na organização porque quer.

\subsection{ENTRINCHEIRAMENTO ORGANIZACIONAL (EO)}

O entrincheiramento organizacional (EO) se refere a uma atitude individual do colaborador desencadeada pela falta de perspectivas em sua carreira. Este fenômeno ocorre 
pela necessidade e pela ausência de alternativas. São diversos fatores pelos quais o indivíduo se sente obrigado a permanecer numa carreira. Os investimentos aplicados durante a sua carreira como tempo, dinheiro, estabilidade, bem como custos emocionais a serem perdidos, levam a uma posição estática e defensiva em sua vida funcional. A mudança de ocupação é um desafio indesejável e requer ruptura do seu "porto seguro", dificultando alguma mudança, tal qual apontam Rodrigues e Bastos (2013). A possível e mencionada ruptura mostra a rigidez na carreira sendo que os prejuízos psicológicos podem ser irreversíveis.

Para Carson e Bedeian (1994), o entrincheiramento é um processo de estagnação, no qual os indivíduos não se adaptam e não se motivam a encontrar alternativas para o seu encaminhamento profissional. Adicionam ainda os autores que alguns sintomas do entrincheiramento podem ser: medo de estigma social, visão da idade como fator de limitação das alternativas de carreira, além da percepção de desequilíbrio na relação custo-benefício da mudança.

Os primeiros estudos realizados no Brasil sobre entrincheiramento organizacional começaram por Baiocchi e Magalhães (2004). A investigação realizada pelos referidos autores tinha como foco os fenômenos negativos do comprometimento organizacional, ou seja, buscava-se um fator que poderia justificar o não comprometimento por parte do indivíduo com as aspirações da organização (BAIOCCHI; MAGALHÃES, 2004). Assim, o conceito de entrincheiramento surgiu da necessidade de se entender os motivos pelo qual o colaborador tinha dificuldade de obter expectativas positivas da sua carreira em relação às organizações. A estagnação da carreira foi percebida como um fenômeno negativo, mas seria necessário compreender este comportamento.

O envolvimento dos colaboradores nos objetivos das organizações sempre foi de grande relevância na produção estratégica das organizações. Para Carson e Bedeian (1994), a preocupação central dos estudos sobre entrincheiramento considerou o indivíduo no processo, e não as organizações. Isto ocorreu pelo fato de que o tema "carreira" passou a ter importância nos estudos das organizações apenas no século XX.

A carreira, assim, não era vista como algo importante para as pessoas e para as organizações, pois o indivíduo tinha a concepção de que carreira era sinônimo de períodos de cargos ocupados por ele, durante a sua vida profissional. A ideia de que, ao entrar numa organização, só sairia ao se aposentar, contribuiu para esta sensação.

Para alguns pesquisadores, o comprometimento organizacional e seus desdobramentos comportamentais, como o entrincheiramento (aspecto considerado nesta pesquisa), se tornaram importante tema para a obtenção de símbolos ocupacionais, tendo em vista que as organizações não podem assegurar os empregos da maneira como ocorria em meados do século XX. A consequência deste fenômeno foi o fim de uma suposta lealdade organizacional, além da limitação dos vínculos que, até então, eram compreendidos como permanentes (SCHEIBLE; BASTOS; RODRIGUES, 2013).

\subsection{INTENÇÃO DE PERMANECER NA CARREIRA (IPC)}

A intenção de permanecer na carreira se confunde com outras dimensões na busca do entendimento e de respostas capazes de solucionar o que, para muitas organizações, se tornou um problema: a retenção de talentos e o maior alinhamento dos colaboradores com os objetivos das organizações (VENELLI-COSTA, 2011). Neste trabalho, testar-se-á a correlação de dimensões já validadas (PSC, COA e EO) e o construto Intenção de Permanecer na Carreira $-I P C$. 
Portanto, dado o referencial teórico-conceitual assumido, foram definidas as seguintes hipóteses para este estudo:

$\mathrm{H}_{1}$ - A Percepção de Sucesso na Carreira (objetiva e subjetiva) do Guarda Civil Metropolitano de São Paulo influencia na Intenção de Permanecer na Carreira dos Profissionais de Segurança Pública;

$\mathrm{H}_{2}$ - Fatores do Comprometimento Organizacional Afetivo contribuem fundamentalmente na Intenção de Permanecer na Carreira da GCM-SP;

$\mathrm{H}_{3}-\mathrm{O}$ Entrincheiramento Organizacional determina a Intenção de Permanecer na Carreira da GCM-SP.

\section{PROCEDIMENTOS METODOLÓGICOS}

Para realização desta pesquisa, assumiu-se abordagem quantitativa, por meio de um estudo elaborado com corte transversal, do qual participaram profissionais da GCM-SP, por meio de aplicação de questionário eletrônico, durante o mês de junho de 2017. Os estudos com corte transversal ou simplesmente estudos transversais são estudos que explicam a situação em que uma população está vivendo em um determinado momento (ROUQUAYROL; ALMEIDA FILHO, 2006).

\subsection{GUARDA CIVIL METROPOLITANA DE SÃO PAULO (GCM-SP) - ASPECTOS GERAIS}

De acordo com as informações disponíveis no site da Prefeitura de São Paulo (2018), a organização da qual fazem parte os respondentes desta pesquisa, foi fundada em 1986, com o papel primordial de proteger os logradouros públicos e as pessoas da metrópole. A partir de 2014, em função do agravamento das questões de segurança pública, passou a ter papel de polícia. Consequentemente, o Guarda Civil Metropolitano passa a assumir também a responsabilidade pelas ações de enfrentamento à criminalidade e à violência, elevando o risco de morte durante sua carreira. No final de 2017, a corporação contava com aproximadamente 5.000 componentes. O plano de carreira da categoria foi instituído pela Câmara Municipal de São Paulo em 2015.

A jornada de trabalho, para a maioria dos componentes, é realizada na escala de 12 horas trabalhadas, seguidas por 36 horas de descanso. Sua estrutura hierárquica é dividida em quatro níveis, com 10 cargos: 3a; 2a e 1a Classe de GCM's e Classe Especial (base da corporação); Classe Distinta e Subinspetor (graduados intermediários); Inspetor (oficiais de comando); Subcomandante e Comandante Geral.

\subsection{INSTRUMENTO DE PESQUISA}

O instrumento foi composto pelas escalas reduzidas de Percepção de Sucesso na Carreira (EPSCR) e Comprometimento Organizacional Afetivo (ECOA), a escala completa de Entrincheiramento Organizacional (ECO) e duas variáveis adaptadas de Van Dam (2008), para medir a intenção de permanecer na organização, na qual o respondente informa, em uma escala do tipo Likert, quanto tempo pretende ficar na carreira de agente de segurança pública e quanto tempo pretende ficar especificamente na carreira da GCM-SP, sendo: 1 = desejo sair imediatamente; 2 = desejo sair em breve; 3 = desejo ficar mais algum tempo; 4 = desejo ficar muito tempo; 5 = desejo ficar até me aposentar. Estas variáveis foram criadas na intenção de se obter a perspectiva do servidor da GCM-SP em relação ao tempo que deseja permanecer na instituição. 


\subsection{ESCALA DE PERCEPÇÃO DE SUCESSO NA CARREIRA}

O instrumento que trata da Percepção de Sucesso na Carreira foi validado por VenelliCosta, em 2010, e publicado em 2011, por Venelli-Costa e Dutra (2011). Cabe ressaltar que o instrumento é dividido em onze fatores para que o indivíduo, por meio da pesquisa survey (com 48 questões) faça a leitura daquilo que ele próprio compreende ser o sucesso de sua própria carreira.

Para este trabalho, adotou-se a escala reduzida de Percepção de Sucesso na Carreira (EPSCR). Esta dimensão apresenta 10 itens divididos em dois fatores que contemplam, de forma comprovada, as necessidades de avaliar a PSC como antecedentes e consequentes de outras variáveis. Os referidos fatores respondem às percepções de sucesso na carreira objetiva e subjetiva, percebidos pelo próprio indivíduo.

Quadro 1 - Fatores da Escala de Percepção de Sucesso na Carreira (versão reduzida)

\begin{tabular}{|c|l|}
\hline \multicolumn{1}{|c|}{ Fator } & \multicolumn{1}{c|}{ Definição } \\
\hline Objetivo & $\begin{array}{l}\text { Envolve resultados que os outros conhecem e normalmente usam para avaliar a } \\
\text { carreira da pessoa, tais como remuneração e status hierárquico. }\end{array}$ \\
\hline Subjetivo & $\begin{array}{l}\text { Envolve resultados que têm valor para a própria pessoa, independentemente dos } \\
\text { resultados que as outras pessoas conhecem sobre a sua carreira, tais como sentir- } \\
\text { se competente, gostar e ter orgulho do que faz, estar em constante } \\
\text { desenvolvimento, inovar e realizar atividades gratificantes. }\end{array}$ \\
\hline
\end{tabular}

Fonte: Venelli-Costa e Dutra (2011)

A versão reduzida cobre a parte conceitual e sustenta a versão completa, não correndo o risco de comprometer os resultados da pesquisa. O quadro 1 apresenta os fatores da versão reduzida da referida escala.

\subsection{ESCALA DE COMPROMETIMENTO ORGANIZACIONAL AFETIVO}

Segundo Siqueira (2008), a escala de Comprometimento Afetivo (ECOA) é uma medida unidimensional que permite avaliar a intensidade com que os empregados nutrem sentimentos positivos e negativos frente à organização que os emprega. Portanto, permite aferir o compromisso de base afetiva. A sua construção compõe 18 sentimentos (15 positivos e 3 negativos), que foram selecionados para representar o vínculo afetivo com a organização.

Cabe ressaltar que Siqueira (2008) propõe uma forma reduzida para a ECOA, pois foram selecionados itens que detinham correlações item-total (homogeneidade) mais elevadas. Dentre os 18 itens, cinco apresentavam homogeneidade igual ou superior a 0,80, para os quais foi calculado um novo coeficiente de precisão, obtendo um valor de Alfa de Cronbach igual a 0,93. Uma relação alta e quase perfeita $(r=0,95 ; p<0,01)$ foi obtida entre as formas completa (18 itens) e reduzida (5 itens) da ECOA. Com elevados índices de confiabilidade que detém em sua forma completa ou reduzida, a ECOA pode ser utilizada em investigações científicas ou em situações práticas de avaliação (SIQUEIRA, 2008; FERNANDES; SIQUEIRA; VIEIRA, 2014), quando for necessário mensurar o grau de comprometimento afetivo nutrido pelo empregado frente à organização empregadora.

\subsection{ESCALA DE ENTRINCHEIRAMENTO ORGANIZACIONAL}

A escala de entrincheiramento organizacional (EEO), proposta por Carson K., Carson P. e Bedeian (1995), é composta de três fatores, conforme pode ser visto no quadro 2. 
Quadro 2 - Fatores da Escala de Entrincheiramento Organizacional

\begin{tabular}{|c|l|}
\hline \multicolumn{1}{|c|}{ Fatores } & \multicolumn{1}{c|}{ Definição } \\
\hline $\begin{array}{c}\text { Investimento na } \\
\text { carreira }\end{array}$ & $\begin{array}{l}\text { Investimentos acumulados em uma carreira de sucesso e que seriam } \\
\text { perdidos, ou que valeriam menos caso fosse buscada uma nova carreira }\end{array}$ \\
\hline Custos emocionais & Custos emocionais associados com a atuação numa nova carreira \\
\hline $\begin{array}{c}\text { Limitações } \\
\text { alternativas }\end{array}$ & $\begin{array}{l}\text { Percepção da ausência de opções disponíveis para o exercício de uma nova } \\
\text { carreira }\end{array}$ \\
\hline
\end{tabular}

Fonte: Adaptado de Carson, Carson e Bedeian (1995).

Os fatores da EEO contemplam aspectos de interpretação do indivíduo em relação à trajetória profissional, tanto em relação ao panorama atual quanto em relação a perspectivas futuras.

\subsection{COLETA DE DADOS}

A pesquisa foi aplicada no Centro de Formação de Segurança Urbana (CFSU), unidade de capacitação da GCM-SP, como também por meio do Google Forms, sendo que o questionário eletrônico foi enviado por e-mail, havendo também, aplicação presencial no próprio CFSU, junto a 74 servidores que estavam em curso de atualização profissional.

Tabela 1 - Dados demográficos da população pesquisada: variáveis quantitativas

\begin{tabular}{cccccc}
\hline Dados Parciais & N & Mínimo & Máximo & Média & Desvio Padrão \\
\hline Idade (anos completos) & 116 & 26 & 60 & 44,03 & 6,385 \\
\hline Anos na GCM & 116 & 3 & 30 & 17,71 & 5,293 \\
\hline $\begin{array}{c}\text { Anos de Trabalho na } \\
\text { Carreira }\end{array}$ & 116 & 9 & 47 & 27,40 & 6,756 \\
\hline Filhos & 116 & 0 & 4 & 1,82 & 1,213 \\
\hline
\end{tabular}

Fonte: Elaborado pelos autores

Por meio eletrônico, obteve-se participação de 42 profissionais da GCM-SP. No total, o estudo contou com a participação de 116 servidores (Figura 1), de todos os níveis hierárquicos da corporação, sendo $33,62 \%$ do sexo feminino e $66,38 \%$ do sexo masculino; a média de idade foi de 44,03 anos (Desvio Padrão = 6,385 e Coeficiente de Variação $=0,145$ ); o tempo médio na instituição indicou 17,71 anos (Desvio Padrão = 5,293 e Coeficiente de Variação $=0,299$ ); $62,1 \%$ dos entrevistados possuem o curso superior ( $25 \%$ com curso superior completo e $37,1 \%$ com curso superior de pós-graduação); $74,1 \%$ são casados e $24,1 \%$ são solteiros; $1,7 \%$ são viúvos e $56,6 \%$ têm entre um e dois filhos.

Além dos aspectos mencionados anteriormente, outro dado em destaque na Tabela 1 é o fato de 19,8\% estarem na GCM-SP há exatos 16 anos. A tabela apresenta também dados sobre as variáveis quantitativas (idade, anos de trabalho na GCM-SP, anos de trabalho em toda carreira e número de filhos) dos dados demográficos.

\subsection{ANÁLISE DOS RESULTADOS}

As análises foram feitas pelo método de equações estruturais, com o algoritmo Partial Least Squares (PLS), utilizando o software SmartPLS 3.0, aplicando regressão múltipla hierárquica sobre cada construto bem como análise de caminhos para o modelo como um todo. 


\subsection{CORRELAÇÕES E REGRESSÃO MÚLTIPLA LINEAR}

A Figura 1 demonstra-se o modelo proposto de pesquisa, considerando o tamanho da amostra, a avaliação de correlações e o modelo de regressão.

Figura 1 - Modelo de pesquisa

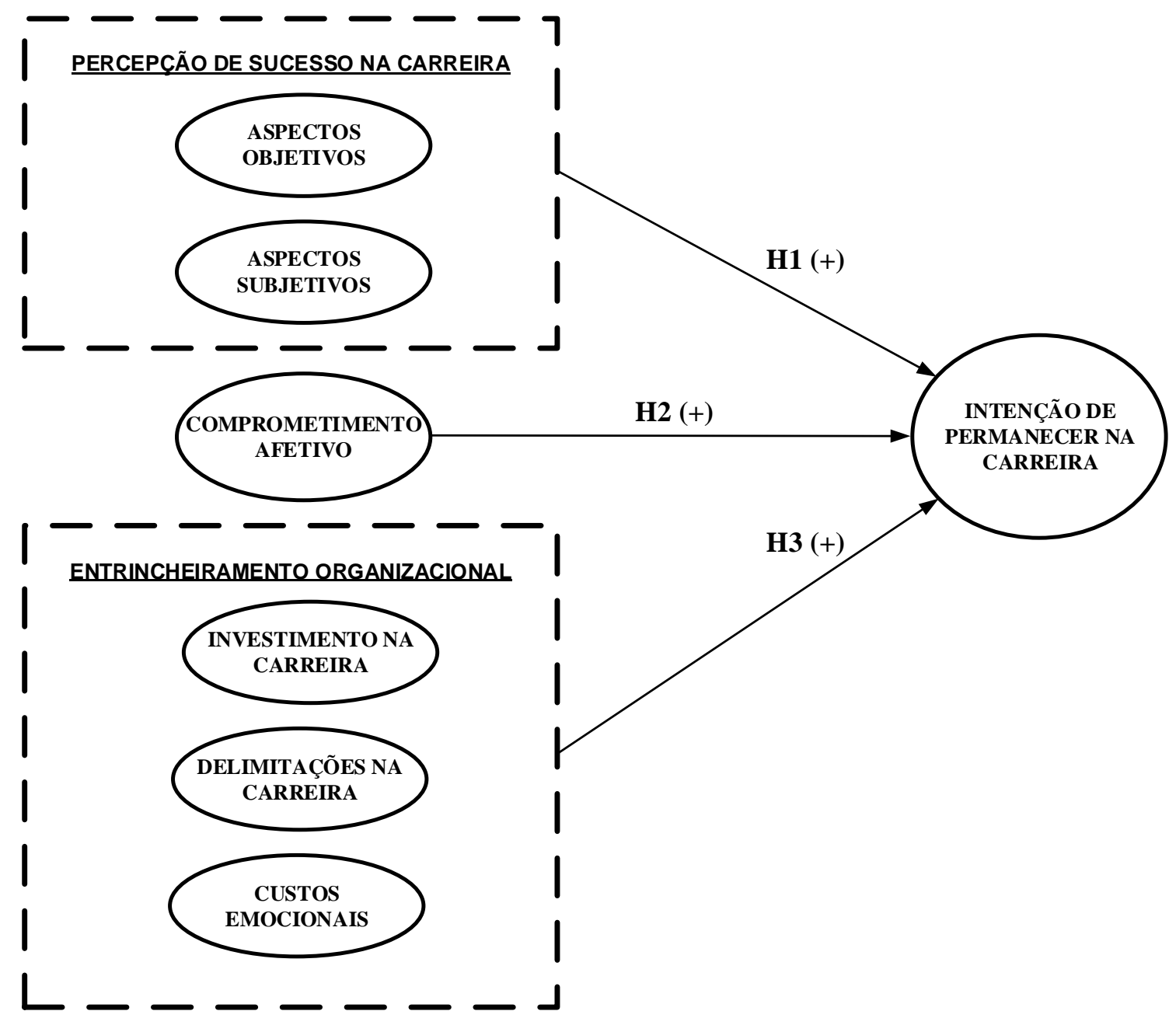

Fonte: Elaborado pelos autores

A escolha dos 116 participantes da pesquisa foi realizada por conveniência, sendo que o cenário empírico ficou acima da amostra mínima necessária para análise de regressão múltipla. A amostra mínima de respondentes para o modelo de pesquisa elaborado é igual a 98 respondentes, de acordo com os critérios de Tabachnick e Fidell (2001), considerando seis preditores à variável dependente.

\section{RESULTADOS E DISCUSSÃO}

\subsection{CONFIABILIDADE}

Para fins de avaliação de confiabilidade das escalas, foram calculados os valores de Alfa de Cronbach de cada uma das dimensões do modelo de pesquisa, a saber: percepção de sucesso na carreira sob aspectos objetivos (PSCO) e subjetivos (PSCS), comprometimento organizacional afetivo (COA), além das dimensões de entrincheiramento organizacional, tais como investimentos na carreira (EOIC), delimitações na carreira (EODC) e custos emocionais 
(EOCE), sendo todas as dimensões relacionadas como antecedentes diretos da intenção de permanecer na carreira de Segurança Pública (IPC). A tabela 2 apresenta os indicadores de Alfa de Cronbach e o número final de variáveis para cada indicador.

Tabela 2 - Valores dos índices de confiabilidade das escalas

\begin{tabular}{lccccccc}
\hline Dimensão & PSCO & PSCS & COA & EOIC & EODC & EOCE & IPC \\
\hline Alfa de Cronbach & 00,78 & 00,77 & 00,91 & 00,85 & 00,71 & 00,73 & 00,97 \\
\hline Número de Itens & C5 & 15 & 15 & Q4 & T3 & D2 & D2 \\
\hline
\end{tabular}

Legenda: percepção de sucesso na carreira sob aspectos objetivos (PSCO) e subjetivos (PSCS), comprometimento organizacional afetivo (COA), entrincheiramento organizacional: investimentos na carreira (EOIC), delimitações na carreira (EODC) e custos emocionais (EOCE); intenção de permanecer na carreira (IPC). Amostra: $\mathrm{n}=116$.

Fonte: Dados da pesquisa

Pelos resultados, nota-se que todos os construtos apresentam valores satisfatórios de confiabilidade, acima de 0,70, conforme recomendado por Cronbach e Meehl (1955). Especificamente no tocante à Escala de Entrincheiramento Organizacional, em busca de melhoria da confiabilidade da escala, foi excluída a terceira questão referente às Delimitações na Carreira. Da mesma forma, a segunda e a quarta questões referentes aos Custos Emocionais foram excluídas.

Quadro 3 - Itens que permaneceram nas escalas

\begin{tabular}{|l|c|}
\hline \multicolumn{1}{|c|}{ Escala } & Itens \\
\hline Percepção de Sucesso na Carreira (objetiva) & $1,2,4,9$ e 10 \\
\hline Percepção de Sucesso na Carreira (subjetiva) & $3,5,6,7$ e 8 \\
\hline Comprometimento Organizacional Afetivo & $1,2,3,4$ e 5 \\
\hline Entrincheiramento Organizacional por investimentos na carreira & $1,2,3$ e 4 \\
\hline Entrincheiramento Organizacional por delimitações na carreira & 1,2 e 4 \\
\hline Entrincheiramento Organizacional por Custos Emocionais & 1 e 3 \\
\hline Intenção de Permanecer na Carreira & 1 e 2 \\
\hline
\end{tabular}

Fonte: Elaborado pelos autores

Ainda em relação à busca por confiabilidade, o mesmo procedimento foi feito em relação à terceira questão da Escala de Intenção de Permanecer na Carreira. Vale registrar, entretanto, que tais ajustes não comprometeram a confiabilidade dos construtos e das escalas, cujos itens considerados na pesquisa se apresentam no quadro 3.

\subsection{ESTATÍSTICA DESCRITIVA DAS ESCALAS}

$\mathrm{Na}$ tabela 3, serão apresentados dados e informações pertinentes ao primeiro objetivo deste trabalho, onde se avalia os níveis dos construtos aqui estudados, visualizamse os valores das estatísticas descritivas das escalas a partir dos seus escores fatoriais.

Tabela 3 - Estatística descritiva das dimensões do instrumento de medida

\begin{tabular}{lccccccc}
\hline \multicolumn{1}{c}{ Dimensão } & PSCO & PSCS & COA & EOIC & EODC & EOCE & IPC \\
\hline Média & 2,21 & 3,94 & 2,93 & 3,29 & 3,14 & 3,36 & 4,08 \\
\hline Mediana & 2,20 & 4,00 & 3,00 & 3,50 & 3,00 & 3,50 & 5,00 \\
\hline Desvio Padrão & 0,74 & 0,73 & 0,85 & 1,12 & 0,95 & 1,21 & 1,24 \\
\hline $\begin{array}{l}\text { Coeficiente de } \\
\text { Variação }\end{array}$ & $33 \%$ & $19 \%$ & $29 \%$ & $34 \%$ & $30 \%$ & $36 \%$ & $30 \%$ \\
\hline
\end{tabular}

Legenda: percepção de sucesso na carreira sob aspectos objetivos (PSCO) e subjetivos (PSCS), comprometimento organizacional afetivo (COA), entrincheiramento organizacional: investimentos na carreira (EOIC), delimitações na carreira (EODC) e custos emocionais (EOCE); intenção de permanecer na carreira (IPC). Amostra: $\mathrm{n}=116$.

Fonte: Dados da pesquisa 
Nota-se que a dimensão com maior valor de mediana foi a variável Intenção de Permanecer na Carreira e o construto com menor valor da mediana foi a Percepção de Sucesso na Carreira, sob os aspectos objetivos.

\subsection{NÍVEIS DE PERCEPÇÃO DE SUCESSO NA CARREIRA (OBJETIVA E SUBJETIVA)}

No cenário pesquisado, os dados demonstraram que o profissional da GCM-SP tem baixa percepção de sucesso objetiva, pois $68 \%$ dos respondentes assinalaram o questionário nas opções 1 (Discordo totalmente) ou 2 (Discordo) nos itens que representam o fator da dimensão objetiva da percepção de sucesso na carreira. A dimensão objetiva do sucesso na carreira se refere aos resultados relativamente visíveis da carreira, como remuneração e promoção (VENELLI-COSTA; DUTRA, 2011). A resposta intermediária (3 - Nem concordo e nem discordo) teve aproximadamente $16,5 \%$ das respostas da população pesquisada. Assim, infere-se que o Guarda Civil Metropolitano de São Paulo não tem segurança em relação aos resultados monetários e de crescimento na carreira. Outra inferência possível é de que existe uma ampla camada da estrutura hierárquica da GCM-SP descontente com a referida questão.

Tabela 4 - Percepção de sucesso na carreira (objetiva)

\begin{tabular}{cc}
\hline Respostas & $\mathbf{N}=\mathbf{1 1 6}$ \\
\hline $1-2$ & $68 \%$ \\
3 & $16,5 \%$ \\
$4-5$ & $15,5 \%$ \\
\hline
\end{tabular}

Legenda: 1 - Discordo totalmente / 2- Discordo / 3 - Nem concordo e nem discordo / 4 - Concordo / 5 Concordo totalmente

Fonte: Dados da pesquisa

É importante ressaltar que houve participação de servidores de todas as esferas hierárquicas, seja qual for o tempo de efetivo exercício na carreira (anos de serviço na GCM-SP). A tabela 4 traz informações sobre as respostas no tocante à percepção de sucesso em âmbito objetivo.

Em relação à percepção de sucesso na carreira em âmbito subjetivo, o Guarda Civil Metropolitano de São Paulo apresenta maior nível, se comparado à percepção em âmbito objetivo, pois $74,25 \%$ dos respondentes sinalizaram positivamente aspectos relacionados à dimensão subjetiva da percepção de sucesso na carreira, que contempla sentimentos de satisfação e realização com a própria carreira (VENELLI-COSTA; DUTRA, 2011).

Tabela 5 - Percepção de sucesso na carreira (subjetiva)

\begin{tabular}{cc}
\hline Respostas & $\mathbf{N}=\mathbf{1 1 6}$ \\
\hline $1-2$ & $7,75 \%$ \\
3 & $18 \%$ \\
$4-5$ & $74,25 \%$ \\
\hline
\end{tabular}

Legenda: 1 - Discordo totalmente; 2 - Discordo; 3 - Nem concordo e nem discordo; 4 - Concordo; 5 - Concordo totalmente

Fonte: Dados da pesquisa

O cenário apresentado na tabela 5 provavelmente se manifesta devido à natureza do trabalho do profissional de segurança pública frente às necessidades e problemas da sociedade brasileira, além da própria formação deste profissional, que é embasada no compromisso em servir ao próximo e na construção de um sólido vínculo de equipe. 


\subsection{NÍVEIS DE COMPROMETIMENTO ORGANIZACIONAL AFETIVO}

O aspecto afetivo é uma das três dimensões do comportamento organizacional, em apropriação idealizada por Meyer e Allen (1991). De acordo com os autores, trata-se do comportamento esperado pelas organizações, pois se trata do alinhamento do colaborador com os objetivos da organização, nos quais os sentimentos de cooperação e de comprometimento são consolidados.

Tabela 6 - Comprometimento organizacional afetivo

\begin{tabular}{cc}
\hline Respostas & $\mathbf{N}=\mathbf{1 1 6}$ \\
\hline $1-2$ & $33,56 \%$ \\
3 & $37,2 \%$ \\
$4-5$ & $29,24 \%$ \\
\hline
\end{tabular}

Legenda: 1 - Nada; 2 - Pouco; 3 - Mais ou menos; 4 - Muito; 5 - Concordo Totalmente.

Fonte: Dados da pesquisa

Na tabela 6 , tem-se que $64,44 \%$ dos respondentes assinalaram entre as respostas 4 (muito) e 5 (extremamente), ou seja, quase $2 / 3$ da população investigada expressa comprometimento organizacional afetivo.

\subsection{NÍVEIS DE ENTRINCHEIRAMENTO ORGANIZACIONAL}

Conforme visto anteriormente, o entrincheiramento organizacional se compõe pelos fatores investimento na carreira, por limitações nas alternativas de carreira e por custos emocionais (RODRIGUES; BASTOS, 2013). Em função das respostas dos Guardas Civis Metropolitanos de São Paulo, depreende-se que o referido profissional não se sente "preso" na carreira pelas limitações de alternativas na carreira, posto que a maior parte do efetivo da GCM-SP possui ou está cursando nível superior, fator que permite vislumbrar a construção de uma nova carreira. Para $52,34 \%$ da população pesquisada, os investimentos na carreira e os custos emocionais ficaram na parte positiva da escala (4 ou 5). Outros $17 \%$ assinalaram a questão intermediária 3 (nem concordo e nem discordo), e os 30,66\% responderam entre 1 (discordo plenamente) e 2 (discordo parcialmente).

Tabela 7 - Entrincheiramento organizacional

\begin{tabular}{cccc}
\hline $\begin{array}{c}\text { ENTRINCHEIRAMENTO } \\
\text { ORGANIZACIONAL }\end{array}$ & $\begin{array}{c}\text { Investimento na } \\
\text { Carreira }\end{array}$ & Limitações de Alternativas & Custos Emocionais \\
\hline $1-2$ & $33,38 \%$ & $39,25 \%$ & $30,66 \%$ \\
3 & $14,28 \%$ & $24 \%$ & $17 \%$ \\
$4-5$ & $52,34 \%$ & $36,75 \%$ & $52,34 \%$ \\
\hline
\end{tabular}

Legenda: 1 - Discordo totalmente; 2 - Discordo; 3 - Nem concordo e nem discordo; 4 - Concordo; 5 - Concordo totalmente. Amostra: $\mathrm{n}=116$.

Fonte: Dados da pesquisa

A depender do segmento, uma dimensão apresenta maior força do que a outra. Especificamente no setor público, Santos (2017) registrou alto índice de entrincheiramento organizacional, cuja característica comum é a sensação que o colaborador tem em permanecer na organização por considerar sua saída uma perda significante. Na tabela 7, constam os dados a respeito das respostas sobre entrincheiramento organizacional, considerados seus três fatores. 


\subsection{NÍVEIS DE INTENÇÃO DE PERMANÊNCIA NA CARREIRA}

A intenção de permanecer na carreira deve ser entendida como a postura de se evitar a saída imediata da organização, como evitar também assumir outra atividade.

Tabela 8 - Permanecer na Guarda Civil Metropolitana de São Paulo

\begin{tabular}{cc}
\hline Respostas & $\mathbf{N}=\mathbf{1 1 6}$ \\
\hline $1-2$ & $20 \%$ \\
3 & $10 \%$ \\
$4-5$ & $70 \%$ \\
\hline
\end{tabular}

Legenda: 1 - Desejo sair imediatamente; 2- Desejo sair em breve; 3 - É indiferente sair ou ficar mais tempo; 4 Desejo ficar muito tempo; 5 - Desejo ficar até me aposentar

Fonte: Dados da pesquisa

Tabela 9 - Permanecer na carreira de segurança pública

\begin{tabular}{cc}
\hline Respostas & $\mathbf{N}=116$ \\
\hline $1-2$ & $20 \%$ \\
3 & $11 \%$ \\
$4-5$ & $69 \%$ \\
\hline
\end{tabular}

Legenda: 1 - Desejo sair imediatamente; 2 - Desejo sair em breve; 3 - É indiferente sair ou ficar mais tempo; 4 Desejo ficar muito tempo; 5 - Desejo ficar até me aposentar

Fonte: Dados da pesquisa

Em relação aos profissionais que participaram desta pesquisa, aproximadamente $70 \%$ assinalaram entre 4 (desejo ficar muito tempo) e 5 (desejo ficar até a aposentadoria), levando em conta tanto a organização (GCM-SP) quanto a carreira (atividade) em si, como pode ser visto nas tabelas 8 e 9.

\subsection{CORRELAÇÕES}

A tabela 10 apresenta os dados referentes às correlações entre as variáveis deste estudo por meio da utilização do $r$ de Pearson.

Tabela 10 - Coeficientes de correlação ( $r$ de Person) entre as variáveis

\begin{tabular}{|c|c|c|c|c|c|c|}
\hline Dimensão & $\begin{array}{l}\text { Percepção } \\
\text { Sucesso } \\
\text { Carreira } \\
\text { objetivo }\end{array}$ & $\begin{array}{c}\text { Percepção } \\
\text { Sucesso } \\
\text { Carreira } \\
\text { subjetivo }\end{array}$ & $\begin{array}{c}\text { Compromisso } \\
\text { Organizacional } \\
\text { Afetivo }\end{array}$ & $\begin{array}{l}\text { Investimento } \\
\text { na } \\
\text { Carreira } \\
\text { (EOIC) }\end{array}$ & $\begin{array}{l}\text { Limitações } \\
\text { na } \\
\text { Carreira } \\
\text { (EODC) }\end{array}$ & $\begin{array}{l}\text { Custos } \\
\text { Emocionais } \\
\text { (EOCE) }\end{array}$ \\
\hline $\begin{array}{l}\text { Percepção Sucesso } \\
\text { Carreira (objetiva) }\end{array}$ & 1,00 & & & & & \\
\hline $\begin{array}{l}\text { Percepção Sucesso } \\
\text { Carreira (subjetiva) }\end{array}$ & $0,32 * * *$ & 1,00 & & & & \\
\hline $\begin{array}{l}\text { Compromisso } \\
\text { Organizacional } \\
\text { Afetivo }\end{array}$ & $0,50 * * *$ & $0,53 * * *$ & 1,00 & & & \\
\hline $\begin{array}{l}\text { Investimento na } \\
\text { Carreira (EOIC) } \\
\end{array}$ & $0,13(0,15)$ & $0,21 * *$ & $0,19 *$ & 1,00 & & \\
\hline $\begin{array}{l}\text { Limitações na } \\
\text { Carreira (EODC) }\end{array}$ & $0,07(0,49)$ & $0,29 * * *$ & $\begin{array}{c}0,14 \\
(0,12)\end{array}$ & $-0,03(0,74)$ & 1,00 & \\
\hline $\begin{array}{l}\text { Custos } \\
\text { Emocionais (EOCE) }\end{array}$ & $0,10(0,29)$ & $0,19 *$ & $0,21^{*}$ & $0,50 * * *$ & $\begin{array}{c}0,03 \\
(0,72) \\
\end{array}$ & 1,00 \\
\hline $\begin{array}{l}\text { Intenção de } \\
\text { Permanecer na Carreira }\end{array}$ & $0,26 * *$ & $0,29 * * *$ & $0,43 * * *$ & $0,42 * * *$ & $\begin{array}{l}-0,01 \\
(0,97)\end{array}$ & $0,38 * * *$ \\
\hline
\end{tabular}

Legenda: $r$ ( $p$-valor); ${ }^{* * *} p<0,001 ; * * p<0,01 ;{ }^{*} p<0,05$

Amostra: $\mathrm{n}=116$.

Fonte: Dados da pesquisa (2017) 
Os índices de correlação foram calculados a partir dos escores médios das variáveis de comprometimento afetivo, entrincheiramento organizacional, intenção de permanecer na carreira de segurança pública e percepção de sucesso na carreira (objetiva e subjetiva).

Para obtenção destes resultados, foram assumidos os critérios para análise de força das correlações, tal qual propuseram Bisquerra, Sarriera e Martinez (2004), a saber: $r=1,00$ (classificada como correlação perfeita); $0,80<r<1$ (classificada como correlação muito alta); $0,60<r<0,80$ (classificada como correlação alta); $0,40<r<0,60$ (classificada como correlação moderada); 0,20 $<r<0,40$ (classificada como correlação baixa) e $0<r<0,20$ (classificada como muito baixa). Nos índices apresentados na Tabela 10 constam correlações significativas entre alguns antecedentes de intenção de permanecer na carreira, como comprometimento organizacional afetivo, entrincheiramento organizacional nos fatores investimentos na carreira e custos emocionais e intenção de permanecer na carreira. A maior correlação com intenção de permanecer na carreira, dentre as variáveis, é o comprometimento organizacional afetivo, tornando-se o preditor mais forte de intenção de permanecer na carreira.

Assim, após obtenção dos dados e sua posterior análise, tem-se o modelo resultante da pesquisa realizada, conforme ilustra a figura 2.

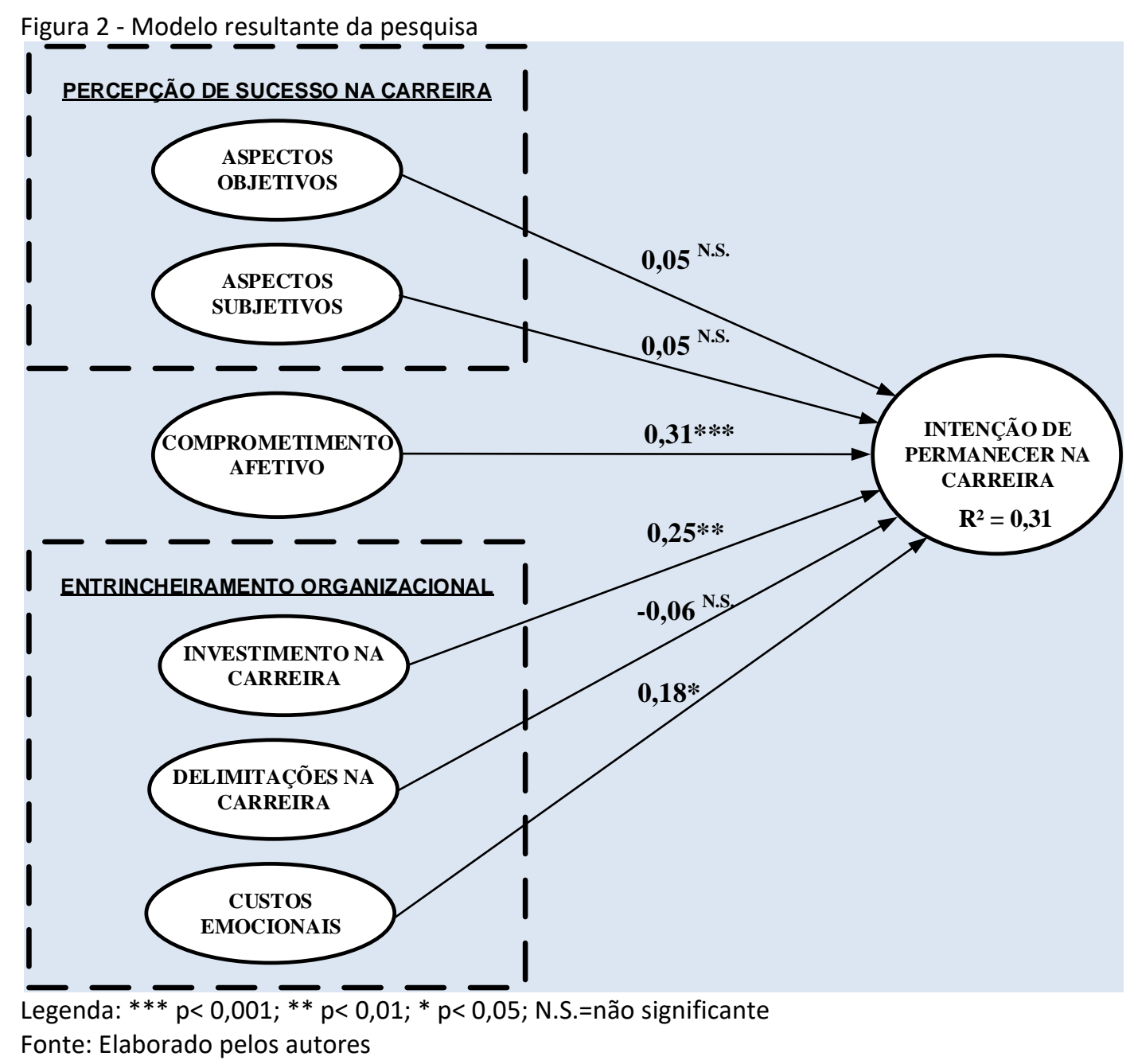

Com base no modelo resultante da pesquisa, tem-se então os resultados das hipóteses assumidas nesse estudo, tal qual demonstra o quadro 4. 
Quadro 4 - Resultados das hipóteses

\begin{tabular}{|c|c|c|}
\hline Hipótese & Conteúdo & Resultado \\
\hline H1 & $\begin{array}{c}\text { A percepção de sucesso na carreira (objetiva e subjetiva) do } \\
\text { Guarda Civil Metropolitano de São Paulo influencia na } \\
\text { intenção de permanecer na carreira dos profissionais de } \\
\text { segurança pública. }\end{array}$ & $\begin{array}{c}\text { Não } \\
\text { confirmada }\end{array}$ \\
\hline H2 & $\begin{array}{c}\text { Fatores do comprometimento organizacional afetivo } \\
\text { contribuem fundamentalmente na intenção de permanecer } \\
\text { na carreira dos profissionais da GCM-SP }\end{array}$ & Confirmada \\
\hline H3 & $\begin{array}{r}\text { O entrincheiramento na carreira determina a intenção de } \\
\text { permanecer na carreira dos profissionais da GCM-SP }\end{array}$ & $\begin{array}{c}\text { Parcialmente } \\
\text { confirmada }\end{array}$ \\
\hline
\end{tabular}

Fonte: Elaborado pelos autores

Assim, constata-se que o desafio empírico assumido demonstra que o comprometimento organizacional afetivo influencia na intenção de permanecer na carreira abordada neste estudo, o que não acontece em relação à percepção de sucesso na carreira. No tocante ao entrincheiramento na carreira, a influência é moderada (parcial).

\section{CONSIDERAÇÕES FINAIS}

Este trabalho contemplou aspectos próprios de intervenção e práticas da gestão de pessoas no âmbito do serviço público, especificamente nas instituições de segurança pública. A contratação de novos servidores por meio de concursos públicos é apenas uma das práticas da gestão pública. Entender os fenômenos que justificam a intenção do servidor em permanecer na carreira além de implantar práticas que estimulem o comprometimento do indivíduo em relação aos objetivos da organização, acaba por se configurar em um dos maiores desafios da gestão de organizações.

Especificamente em relação ao cenário abordado neste trabalho, constatou-se que fatores com respostas e sinalizações positivas diziam respeito a características subjetivas e emocionais. As respostas dos Guardas Civis confirmam a existência da Percepção de Sucesso na Carreira subjetiva, ou seja, este profissional nutre o orgulho de exercer a sua atividade, embora se veja frustrado com as recompensas objetivas da carreira, tais como salário e previdência por exemplo. Este resultado teve a influência determinante por parte das mulheres da GCM-SP, pois 58,4\% delas responderam positivamente às questões da Percepção de Sucesso na Carreira subjetiva. Entretanto, o profissional da GCM-SP se identifica, de alguma forma, com algumas variáveis da dimensão subjetiva da percepção de sucesso na carreira, ainda que não de maneira completa, não permitindo assumir que esta dimensão é um forte influenciador na intenção de permanecer na carreira.

$\mathrm{Na}$ análise do comprometimento organizacional afetivo é necessário observar alguns critérios para a melhor interpretação dos resultados. Segundo Siqueira (2008), deve-se considerar que quanto maior for o escore médio, mais forte é o compromisso afetivo com a organização. Neste trabalho, os valores entre 1 e 2 resultantes do sentimento negativo do Guarda Civil Metropolitano foi de 32\% dos respondentes. Isto pode indicar um frágil compromisso afetivo pela instituição; porém, a pesquisa demonstra que $37,2 \%$ sugerem ter dúvidas em relação ao seu vínculo afetivo em relação à instituição. Este fenômeno causa inquietação por conta da ausência de motivos concretos, o que talvez mereça investigação em trabalhos futuros. Os outros $29,24 \%$ dos respondentes indicaram convicção de seu comprometimento organizacional afetivo. 
Assim, depreende-se, em função do cenário empírico tratado nesta pesquisa, que fatores como investimento e custos emocionais ocupam lugar de destaque no tocante à intenção de permanecer na carreira de segurança pública, dando mostras de entrincheiramento organizacional. Portanto, pelo que se obteve nesta pesquisa, pode-se concluir que os fatores que influenciam a permanência na carreira na GCM-SP são o comprometimento organizacional afetivo e o entrincheiramento organizacional, sendo este ocasionado por investimentos na carreira e custos emocionais.

Este trabalho apresenta, em termos de contribuição acadêmica, possibilidades de reflexão sobre aspectos que se relacionem a estratégias para retenção de pessoas na organização como também debate sobre as peculiaridades de gestão de carreira em organizações com rígido apego à hierarquia. Quanto às contribuições práticas, os resultados podem ser úteis para gestores de equipes, de modo a indicar caminhos para se estimular o comprometimento organizacional por parte dos profissionais.

Entretanto, é mister reconhecer que o trabalho apresenta limitações, como o fato de tratar de apenas uma organização, em uma dada realidade local. Outra limitação diz respeito à opção metodológica assumida, de teor quantitativo. Assim, para pesquisas futuras, vale sugerir iniciativas de caráter qualitativo de modo a investigar, com maior profundidade, aspectos inerentes à intenção do indivíduo em permanecer na carreira. Outra indicação é ampliar o campo de análise, contemplando profissionais de outros segmentos e de outras regiões.

\section{REFERÊNCIAS}

BAIOCCHI, A. C.; MAGALHÃES, M. Relações entre Processos de Comprometimento, Entrincheiramento e Motivação Vital em Carreiras Profissionais. Revista Brasileira de Orientação Profissional, v. 5, n.1, p. 63-69, 2004.

BANDEIRA, M. L.; MARQUES, A. L.; VEIGA, R. T. As dimensões múltiplas do comprometimento organizacional: um estudo na ECT/MG. Revista de Administração Contemporânea, v. 4, n. 2, p. 133-157, 2000. DOI: http://dx.doi.org/10.1590/S141565552000000200008.

\section{BASTOS, A. V. B. Comprometimento organizacional: a estrutura dos vínculos do} trabalhador com a organização, a carreira e o sindicato. Tese (Doutorado em Psicologia) Universidade de Brasília, 1994.

BISQUEIRA, R.; SARRIERA, J. C.; MARTINEZ, F. Introdução à estatística: enfoque informático com o pacote estatístico SPSS. Porto Alegre: Artmed, 2004.

CARSON. K.; BEDEIAN, A. Career commitment: construction of a measure and examination of its psychometric properties. Journal of Vocational Behavior, v.44, n.3, p.237-262, 1994. DOI: https://doi.org/10.1006/jvbe.1994.1017.

CARSON, K. D.; CARSON, P. P.; BEDEIAN, A. G. Development and construct validation of a career entrenchment measure. Journal of Occupational and Organizational Psychology, v.68, p. 301-320, 1995. DOI: https://doi.org/10.1111/j.2044-8325.1995.tb00589.x. 
COETZEE, M.; ESTERHUIZEN, K. Psychological career resources as predictors of African graduates' coping resources: an exploratory study. South African Journal of Industrial Psychology, v. 36, n. 1, 2010. DOI: https://doi.org/10.1080/14330237.2013.10820648.

COSTA, A. R.; VIEIRA, A. M. Percepção de sucesso na carreira, bem-estar no trabalho e desempenho: um estudo com professores universitários. Qualit@s (UEPB), v. 16, p. 1-13, 2014. DOI: http://dx.doi.org/10.18391/qualitas.v15i2.2061.

CRONBACH, L. J.; MEEHL, P. E. Construct validity in psychological tests. Psychological Bulletin, v. 52, n. 4, p. 281-302, 1955. DOI: http://dx.doi.org/10.1037/h0040957.

DUTRA, J. S. As Pessoas na Organização. São Paulo: Editora Gente, 2002.

FERNANDES, C. M.; SIQUEIRA, M. M. M.; VIEIRA, A. M. Impacto da percepção de suporte organizacional sobre o comprometimento organizacional afetivo: o papel moderador da liderança. Revista Pensamento Contemporâneo em Administração, v. 8, n. 4, p. 140-162, 2014. DOI: https://doi.org/10.12712/rpca.v8i4.396.

FERNANDES, C. A.; VENELLI-COSTA, L.; VIEIRA, A. M.; AMORIM, W. A. C. Formação das competências do estrategista: um estudo dos oficiais da polícia militar. Revista de Carreiras e Pessoas, v. 4, n. 1, p. 52-69, 2014. DOI: https://doi.org/10.20503/recape.v4i1.19412.

JUDGE, T. A.; CABLE, D. M.; BOUDREAU, J. W.; BRETZ, R. D. An empirical investigation of the predictors of executive career success. Personnel Psychology, v. 48, p. 485-519, 1995. DOI: https://doi.org/10.1111/j.1744-6570.1995.tb01767.x.

LONDON, M.; STUMPH, S. Managing careers. Reading, MA: Addison-Wesley, 1982.

MEYER, J. P.; ALLEN, N. J. A three-component conceptualization of organizational. Human Resource Management Review, 1991. DOI: https://doi.org/10.1016/1053-4822(91)90011-Z.

MEYER, J. P.; ALLEN, N. J.; SMITH, C. A. Commitment to organizations and occupations: extension and test of a three-component conceptualization. Journal of Applied Psychology, v. 78, n. 4, p. 538-551, 1993. DOI: http://dx.doi.org/10.1037/0021-9010.78.4.538.

PREFEITURA DE SÃO PAULO. Secretarias: Segurança Urbana - Guarda Civil. Disponível em www.prefeitura.sp.gov.br/cidade/secretarias/seguranca_urbana/guarda_civil/Acesso em 12/05/18.

RODRIGUES, A. P. G.; BASTOS, A. V. B. Os vínculos de comprometimento e entrincheiramento presentes nas organizações públicas. Revista de Ciências da Administração, v. 15, n. 36, p. 143-158, 2013. DOI: https://doi.org/10.5007/21758077.2013v15n36p143.

ROUQUAYROL, M. Z; ALMEIDA FILHO, N. Epidemiologia e saúde. Rio de Janeiro: Guanabara Koogan, 2006.

ROWE, D. E. O.; BASTOS, A. V. B. Vínculos com a carreira e produção acadêmica: comparando docentes de IES públicas e privadas. Revista de Administração Contemporânea, v. 14, n. 6, p. 1011-1030, 2010. DOI: http://dx.doi.org/10.1590/S1415- 


\section{3.}

SANTOS, A. P. Comprometimento e Entrincheiramento em Carreiras do Setor Público: Estudo Exploratório e Confirmatório. Cadernos Gestão Pública e Cidadania, v. 22, n. 73, p. 355-378, 2017. DOI: http://dx.doi.org/10.12660/cgpc.v22n73.56434.

SCHEIBLE, A. C. F.; BASTOS, A. V. B.; RODRIGUES, A. C. A. Comprometimento e entrincheiramento na carreira: integrar ou reconstruir os construtos? Uma exploração das relações à luz do desempenho. Revista de Administração, v. 48, n. 3, p. 530-543, 2013. DOI: http://dx.doi.org/10.5700/rausp1104.

SINDGUARDAS. Sindicato dos Guardas Civis Metropolitanos de São Paulo. Institucional. Disponível em: www.sindguardas-sp.org.br. Acesso em: 28/03/2018.

SIQUEIRA, M. M. M.(Org.). Medidas do comportamento organizacional: Ferramentas de diagnóstico e de gestão. Porto Alegre: Artmed, 2008.

TABACHNICK, B.; FIDELL, L. S. Using multivariate statistics. New York: Harper Collins, 2001.

VAN DAM, K. Time frames for leaving: an explorative study of employees intentions to leave the organization in the future. Career Development International, v. 13, n. 6, p. 560-571, 2008. DOI: https://doi.org/10.1108/13620430810901697.

VENELLI-COSTA, L. A relação entre a percepção de sucesso na carreira e o

comprometimento organizacional: um estudo entre professores de Universidades privadas selecionadas da Grande São Paulo. Tese (Doutorado em Administração) - Universidade de São Paulo, 2010.

VENELLI-COSTA, L.; DUTRA, J. S. Avaliação da Carreira no Mundo Contemporâneo: Proposta de um Modelo de Três Dimensões. Revista de Carreiras e Pessoas, v. 1, n.1, p. 1-22, 2011. DOI: https://doi.org/10.20503/recape.v1i1.6493. 